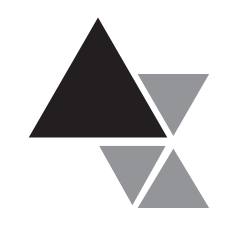

\title{
RESÍDUOS DE ANTIMICROBIANOS EM LEITE - UMA REVISÃO
}

\author{
José Guilherme Prado Martin ${ }^{1}$
}

Uma das maiores preocupações nos dias atuais quanto à segurança alimentar consiste na produção de alimentos livres de contaminantes. Desse ponto de vista, é imprescindível que seja garantida a produção de alimentos que não representem riscos à saúde dos consumidores. O leite é um produto de origem animal bastante susceptível à contaminação por resíduos de antimicrobianos em decorrência da utilização indiscriminada de drogas veterinárias para tratamento do rebanho leiteiro. $\mathrm{O}$ respeito às recomendações dos organismos internacionais e à legislação brasileira deve ocorrer em toda a cadeia de produção. A presente revisão aborda a problemática da ocorrência de antimicrobianos em leite, com enfoque na segurança alimentar, relacionando o tema à legislação vigente no país e discutindo alternativas para seu controle.

Palavras-chave: resíduos, antimicrobianos, leite, segurança alimentar.

\section{ANTIMICROBIALS RESIDUES IN MILK - A REVIEW}

One of the most concerns in food safety nowadays is on food free of contaminants production. From this point of view, it is essential to ensure food production that does not represents risk to consumers health. Milk is an animal origin product very likely to contamination by antimicrobial residues due to indiscriminate use of veterinaries drugs for dairy cattle treatment. The respect to international organizations recommendations and Brazilian law must to occur in all production chain. This review deals with the problematic of antimicrobial occurrence in milk, focused in food safety, relating the theme to the country current law and discussing alternatives to its control.

Key-words: residues, antimicrobial, milk, food safety.

\footnotetext{
${ }^{1}$ Doutorando do Programa de Pós-graduação em Ciência e Tecnologia de Alimentos - Escola Superior de Agricultura Luiz de Queiroz (ESALQ), Universidade de São Paulo (USP), Depto. de Agroindústria, Alimentos e Nutrição, Piracicaba, SP. Correspondência: Av. Pádua Dias, 11, CEP 13418-900, Piracicaba, SP. E-mail: gui.pmartin@gmail.com.
} 


\section{INTRODUÇÃO E DISCUSSÃO}

Nos dias atuais, uma das maiores preocupações relacionadas à segurança alimentar consiste em evitar ou diminuir a ocorrência de contaminantes em alimentos, atribuída ao uso indiscriminado de pesticidas e drogas veterinárias ou às contaminações ambientais. Além de colocar em risco a saúde dos consumidores, resíduos em alimentos comprometem relações comerciais, principalmente no âmbito internacional, que envolvam produtos in natura $\mathrm{e}$ processados de origem animal ${ }^{[1]}$.

A Segurança Alimentar e Nutricional consiste na realização do direito de todos ao acesso regular e permanente a alimentos de qualidade, e abrange, entre outros aspectos, a garantia da qualidade biológica, sanitária, nutricional e tecnológica dos alimentos ${ }^{[2]}$. Desse ponto de vista, é imprescindível que se garanta a inocuidade de produtos de origem animal por meio do controle de resíduos, a fim de que se respeitem, dessa forma, os direitos universais ao bem-estar social e à saúde do homem. Todos os países, independentemente de sua condição social e econômica, devem oferecer condições para que sua agricultura se desenvolva de modo a satisfazer todas as necessidades alimentares de sua população, em quantidade e qualidade suficientes para a garantia de uma vida digna e sadia ${ }^{[3]}$.

O leite é um dos alimentos mais completos em termos nutricionais e fornece ao homem componentes essenciais para o desenvolvimento e manutenção da saúde, como proteínas, lipídeos, carboidratos e vitaminas ${ }^{[4]}$. Constitui, junto a seus derivados, importante fonte de nutrientes para a população de muitos países e o volume que movimenta no comércio internacional é bastante significativo. Devido suas características nutricionais, consiste em um meio favorável ao desenvolvimento de micro-organismos patogênicos, podendo também estar contaminado com resíduos de medicamentos veterinários, praguicidas e outros contaminantes químicos ${ }^{[5]}$.

A magnitude do impacto na saúde pública da ingestão de alimentos com resíduos de antibióticos ainda não está completamente elucidada. No entanto, há evidências suficientes para que cause apreensão. É irrefutável o fato de que a exposição contínua a antimicrobianos é responsável pelo surgimento de resistência bacteriana, dependendo de seus períodos de exposição e níveis de concentração. Antibióticos são utilizados extensamente na pecuária, agricultura e piscicultura, e um dos agravantes da problemática reside na sua utilização em doses sub-terapêuticas ${ }^{[6]}$. Inicialmente, eram aplicados apenas com propósito terapêutico; porém, com o desenvolvimento de novos conhecimentos e a descoberta de novos compostos, passaram a ser empregados como preventivos de doenças e como promotores de crescimento, principalmente em rebanhos ${ }^{[7]}$.

O Brasil figura entre os maiores produtores de leite do mundo. Em 2010 foram produzidos cerca de 30 bilhões de quilos de leite no País ${ }^{[8]}$. O crescimento da produção decorre, principalmente, da grande extensão territorial disponível para a criação de gado, bem como da existência de sistemas de produção viáveis. Nesse âmbito, cabe salientar a favorável relação comercial com países importadores, situando o país na condição de nação exportadora de agro-negócio mundial ${ }^{[9]}$. A exigência cada vez maior de alimentos de qualidade por parte dos agentes comerciais internacionais exige do país um rigoroso controle do leite e derivados produzidos. Logo, tornase necessária a aplicação de medidas adequadas para que se garantam sua inocuidade e idoneidade para o uso ao qual se destinam.

A presente revisão tem como objetivo abordar a problemática da presença de antimicrobianos em leite na esfera da segurança alimentar, relacionando o tema principalmente à legislação vigente no país e discutindo alternativas para o controle da presença de resíduos de antimicrobianos no leite.

\section{ANTIMICROBIANOS NO LEITE}

De acordo com o Codex Alimentarius, no momento em que for disponibilizado aos consumidores, o leite não deve conter nenhum contaminante em níveis que coloquem em risco sua saúde. O estado de saúde das vacas leiteiras deve ser controlado para que não constituam riscos para a saúde pública; o tratamento e a prevenção de doenças no rebanho devem ser feitos apenas com medicamentos veterinários autorizados e de maneira que não afete negativamente a inocuidade e idoneidade do leite ${ }^{[5]}$.

Antibióticos são comumente utilizados para tratar mastites e outras infecções em vacas leiteiras 
e podem ser detectados no leite após administração intramamária, intramuscular, intrauterina, oral ou subcutânea ${ }^{[10]}$. Outra fonte de antibióticos em leite, menos comum, porém possível, é sua introdução voluntária fraudulenta para aumentar a durabilidade do produto ${ }^{[11]}$.

Dentre os principais antimicrobianos administrados ao rebanho leiteiro, encontram-se os $\beta$-lactâmicos (representados principalmente pelas penicilinas e cefalosporinas) ${ }^{[12]}$, os aminoglicosídeos, o cloranfenicol, as tetraciclinas e os macrolídeos [13]. Estudo realizado no Brasil aponta o grupo dos $\beta$-lactâmicos como o mais difundido entre os antibióticos utilizados no tratamento de infecções em vacas leiteiras na região Sul do País, representando $38,22 \%$ do total de antibióticos, seguido de aminoglicosídeos (25,19\%), tetraciclinas (15,41\%), macrolídeos $(7,59 \%)$ e cefalosporinas $(4,19 \%){ }^{[11]}$. Estudos acerca das classes de antibióticos mais frequentemente utilizadas pelos produtores de leite são importantes à medida que poderiam auxiliar na sua detecção pelos órgãos fiscalizadores, no intuito de se combater o uso indiscriminado dessas drogas.

A veiculação do antibiótico para o leite depende de uma série de fatores, a saber: dose administrada, natureza do veículo utilizado (se aquoso ou oleoso), do tipo do antibiótico e de fatores intrínsecos ao animal tratado. Calcula-se que cerca de 30 a $80 \%$ do antibiótico aplicado diretamente na glândula mamária passem da corrente sanguínea para o leite; geralmente, as preparações aquosas persistem por três dias; as oleosas são eliminadas após cinco dias ou mais ${ }^{[14]}$. Assim, devemse respeitar rigorosamente os períodos de suspensão prescritos para cada tipo de medicamento administrado no período próximo à ordenha; caso contrário, todo o leite deve ser descartado ${ }^{[5]}$.

A presença de resíduos de antibióticos em leite é indesejável por ocasionar uma série de problemas. Dentre eles, destacam-se os relacionados à perda de eficiência no processo de produção de derivados, como queijos e iogurtes, e aos riscos que oferece à saúde pública.

Os prejuízos para os laticínios em decorrência de antibióticos presentes na matéria-prima são inúmeros. Ao provocar inibição parcial das bactérias lácticas utilizadas nos processos de fermentação, com consequente diminuição do $\mathrm{pH}$, comprometem a qualidade sensorial dos derivados do leite, além de aumentar os riscos de crescimento de coliformes e bactérias patogênicas. Cabe salientar que, na maioria das vezes, o processo de pasteurização ou processamento não reduz a atividade dos antibióticos, e até mesmo traços de antibióticos $(0,1$ unidade/ml) podem inibir completamente cepas de bactérias de fermentos lácteos ${ }^{[14]}$. Tendo em vista tais problemas, principalmente no leite que constitui matériaprima para a fabricação de derivados, a ausência de contaminantes residuais tem sido um dos pontos mais visados pela indústria de laticínios ${ }^{[15]}$.

Quanto à questão de saúde pública, diferentes tipos de riscos estão implicados na problemática da presença de antimicrobianos em leite, tais como os microbiológicos, os imunopatológicos e os toxicofarmacológicos.

Os microbiológicos consistem basicamente na seleção de cepas resistentes, comprometendo o desequilíbrio da flora intestinal e tratamentos médicos futuros no homem ${ }^{[16]}$. A maioria da população humana é frequentemente exposta a baixas doses desse tipo de resíduo, o que pode ter efeitos graves a longo prazo ${ }^{[17]}$. O surgimento de resistência a antimicrobianos em bactérias traz grandes obstáculos a procedimentos médicos tanto em humanos quanto em animais, resultando em aumento das taxas de mortalidade e morbidade na população e dos custos de tratamento de várias enfermidades ${ }^{[18]}$. Tanto as drogas de uso terapêutico consagrado quanto aquelas de inserção recente no mercado de fármacos vêm se tornando ineficientes no combate a determinadas bactérias ${ }^{[19]}$.

Os riscos imunopatológicos incluem $\mathrm{O}$ desencadeamento de reações de hipersensibilidade e choque anafilático em indivíduos susceptíveis, embora sua ocorrência seja relativamente rara ${ }^{[20]}$. Lederer ${ }^{[21]}$ relata casos de reações de hipersensibilidade em indivíduos logo após ingestão de leite contaminado com penicilina; para o desencadeamento da reação, basta que o antibiótico esteja presente no leite, mesmo que em pequenas quantidades ${ }^{[19]}$. Cerca de 5 a $10 \%$ da população mundial são hipersensíveis à penicilina, e frações muito pequenas de $1 \mathrm{ppb}$ são suficientes para desencadear um processo alérgico ${ }^{[22]}$.

Quanto aos riscos toxicológicofarmacológicos, o principal consiste no consumo de leite contaminado com antimicrobianos por gestantes, devido ao risco de exposição do feto a substâncias 
com potencial efeito teratogênico, podendo causar toxicidade e alterações no desenvolvimento ósseo fetal ${ }^{[23]}$. Pode ocorrer também o desenvolvimento de anemia aplásica, relacionada principalmente à ingestão de cloranfenicol ${ }^{[24]}$, e ação carcinogênica associada aos nitrofuranos ${ }^{[16]}$.

Além dos prejuízos na cadeia produtiva do leite e dos riscos à saúde pública, a presença de antimicrobianos em leite também consiste em sério perigo ambiental, principalmente pelo fato desses resíduos serem muitas vezes descartados em ambientes aquáticos logo depois de seu consumo ${ }^{[25]}$. Para evitar esse tipo de contaminação ambiental, os produtores deverão reduzir ao máximo a eliminação de resíduos químicos das operações de limpeza e desinfecção durante todo o processo de operação da ordenha ${ }^{[5]}$.

Os índices de contaminação de leite por resíduos de antimicrobianos variam bastante dentre os estudos realizados. Sulfamerazina e ciprofloxacina foram detectados em 1,4\% de amostras de leite comercializado na Coréia ${ }^{[26]}$. Em pesquisa realizada na região de Castilla, Espanha, foram encontradas $1,7 \%$ de amostras de leite contaminadas por antibióticos, dos quais $29,8 \%$ eram $\beta$-lactâmicos ${ }^{[27]}$. Índices superiores $(40,8 \%)$ foram detectados em amostras de leite provenientes do Irã ${ }^{[28]}$. No Brasil, resíduos de antimicrobianos foram detectados em $11,4 \%$ das amostras de leite provenientes de quatro regiões leiteiras do País ${ }^{[29]}$, número próximo ao encontrado em leite pasteurizado comercializado no Estado de Goiás (9,95\%) ${ }^{[30]}$. Índices bastante superiores $(33,3 \%)$ foram detectados em amostras de leite coletadas na região do Triângulo Mineiro ${ }^{[31]} \mathrm{e}$ no Estado do Paraná (41,3\%) ${ }^{[24]}$. Em estudo realizado no Rio Grande do Norte, contudo, nenhuma das 32 amostras de leite cru comercializado no município de Mossoró continha resíduos de antimicrobianos ${ }^{[32]}$.

\section{LEGISLAÇÃO}

Nem todas as drogas e compostos químicos aos quais os animais ficam expostos conferem perigos à saúde. Portanto, torna-se importante destacar o conceito de Limite Máximo de Resíduo (LMR). Tratase de um limite de segurança - ou de tolerância que o alimento pode conter, sem causar prejuízo à integridade orgânica de seres humanos e animais. Estes limites, determinados em instituições de comprovada idoneidade científica, por meio de rigorosos estudos toxicológicos, são recomendados, após uma série de análises, por órgãos internacionais competentes, como a Food and Agriculture Organization (FAO). A determinação dos LMRs dos antibióticos é considerada o principal parâmetro para validação dos testes de detecção de resíduos de drogas em alimentos ${ }^{[14]}$. No Brasil, o estabelecimento dos LMRs cabe ao Ministério da Saúde. Caso contrário, são utilizados os internalizados no MERCOSUL, os recomendados pelo Codex Alimentarius, os que constam nas Diretivas da União Européia e os utilizados pela americana Food and Drug Administration.

A Resolução GMC no 54/2000 (MERCOSUL) [33], que harmoniza alguns antimicrobianos, seus respectivos valores de LMRs e de Ingestão Diária Aceitável (IDA), é utilizada pelos órgãos brasileiros de fiscalização e controle. Segundo esta resolução, os valores de LMR para benzilpenicilina, procaína, ampicilina e amoxicilina não devem ultrapassar os 4 $\mu \mathrm{g} / \mathrm{kg}$; para diidroestreptomicina e estreptomicina, os limites são de $200 \mu \mathrm{g} / \mathrm{kg}$; para neomicina, há limites de $500 \mu \mathrm{g} / \mathrm{kg}$; para eritromicina, os limites são de 40 $\mu \mathrm{g} / \mathrm{kg}$; tetraciclina, oxitetraciclina, clortetraciclina, ceftiofur, sulfametazina, sulfadimetoxina e sulfatiazol possuem limites de até $100 \mu \mathrm{g} / \mathrm{kg}$; cloranfenicol não pode ser detectado em quaisquer quantidades residuais. Em relação à IDA há valores de 0 a 30 g/ $\mathrm{kg}$ p.c. (peso corpóreo) para benzilpenicilina, procaína, tetraciclina, oxitetraciclina e clortetraciclina; de 0 a 50 $\mu \mathrm{g} / \mathrm{kg}$ p.c. para diidroestreptomicina, estreptomicina, sulfametazina, sulfadimetoxina e sulfatiazol; e de 0 a $60 \mu \mathrm{g} / \mathrm{kg}$ p.c para neomicina. Eritromicina, ampicilina, amoxicilina, ceftiofur e cloranfenicol não apresentam valores de IDA estabelecidos.

De acordo com o Plano Nacional de Controle de Resíduos em Produtos de Origem Animal (PNCR) ${ }^{[34]}$, o critério de inclusão de resíduos para monitoramento da qualidade de alimentos de origem animal em programas de diversos países é feito sob as seguintes condições: geração de resíduos pela substância; o grau de toxicidade do resíduo para a saúde do consumidor; o potencial de exposição da população ao resíduo (considerando-se hábitos alimentares, poder aquisitivo, tecnologia para a produção de alimentos para consumo animal), poluição ambiental; mau emprego das drogas formadoras de resíduos (com a consequente aplicação das boas práticas agrícolas e pecuárias); uso de metodologias adequadas para 
análise, que sejam confiáveis, exequíveis e compatíveis com os recursos laboratoriais existentes; implicações nas relações comerciais internacionais dos resíduos que possam constituir barreiras às exportações de alimentos de origem animal; e problemas que tragam risco à saúde pública.

Especificamente para o leite, o Plano Nacional de Controle de Resíduos em Leite (PCRL) fornece subsídios para a melhoria de sua produção e produtividade em todo o território nacional. As ações a serem implementadas pelo PCRL seguem uma recomendação própria nos casos em que não existe legislação específica; inicialmente procede-se a identificação da propriedade de origem do leite, seguida de uma visita ao local para investigação, orientação e colheita das amostras que seguirão para análise e, por conseguinte, a análise propriamente dita; no caso de resultado positivo, no qual for confirmada a violação do limite máximo de resíduo, notifica-se imediatamente o proprietário, a Inspeção Federal e a Defesa Sanitária Animal, impedindo-se a propriedade de comercializar o produto até que as análises tornemse negativas. Para o caso de confirmação da utilização de substâncias proibidas, notifica-se primeiramente o proprietário, cabendo-lhe recurso para análise da contraprova; se o resultado da contraprova for confirmado, o proprietário fica sujeito às sanções decorrentes de sindicância da Polícia Federal e sua propriedade fica proibida de comercializar seus produtos pelo prazo de dois meses ${ }^{[34]}$.

Quanto à fiscalização sanitária e industrial, sua competência cabe a diferentes órgãos públicos, de acordo com a classificação da produção industrial. Quando o comércio é interestaduale/ou internacional, a fiscalização da indústria é feita pelo Departamento de Inspeção de Produtos de Origem Animal (DIPOA), da Secretaria de Defesa Agropecuária (SDA), ligada ao Ministério da Agricultura, Pecuária e Abastecimento (MAPA). Se a indústria realiza comércio dentro do mesmo Estado, cabe a órgãos estaduais a fiscalização; da mesma forma, quando o comércio de uma indústria se restringe apenas ao município onde se encontra instalada, a fiscalização compete à esfera municipal ${ }^{[35]}$.

No ano de 2002 surgiu o Programa de Análise de Resíduos Veterinários em Alimentos de Origem Animal (PAMVet), a partir de discussões sobre o tema promovidas pela Agência Nacional de Vigilância Sanitária (ANVISA) em anos anteriores. Mais tarde, a própria ANVISA define o Programa pela Resolução RDC no 253, de 16 de setembro de 2003, com o objetivo de operacionalizar sua competência legal de controlar e fiscalizar a presença de resíduos de medicamentos veterinários em alimentos. $\mathrm{O}$ primeiro relatório do PAMVet, produzido durante os anos de 2002 e 2003, permitiu um primeiro esboço do perfil dos medicamentos veterinários no leite consumido pela população brasileira. Esses dados foram de grande importância, pois permitiram o aprofundamento dos debates internos, no intuito de melhorar o controle sanitário de alimentos, mais especificamente do leite, dando subsídios para a ampliação da capacidade do governo de promover medidas preventivas de alcance em toda a cadeia produtiva do leite ${ }^{[36]}$.

\section{LEITE ORGÂNICO: UMA ALTERNATIVA?}

A relação saúde versus alimentação saudável tem conquistado destaque cada vez maior entre os consumidores. A ideia de consumo consciente ganha força e muitas vezes pauta a compra de produtos obtidos com responsabilidade social e ambiental, mesmo que com preços mais elevados ${ }^{[7]}$. Os motivos que levam os consumidores a comprar produtos orgânicos são variados. Em países como Alemanha, Inglaterra, Austrália, Estados Unidos, França e Dinamarca, as principais motivações estão relacionadas à saúde, seguidos da questão ambiental e do sabor dos alimentos produzidos pela agricultura orgânica. Em pesquisa realizada em Curitiba em feiras orgânicas, a principal razão para a compra de produtos orgânicos é o benefício à saúde ${ }^{[37]}$. Logo, o crescimento da demanda por esses produtos, relacionado a uma alimentação mais saudável, tem impulsionado os mercados à busca de soluções para os problemas de saúde pública relacionados ao consumo de alimentos contaminados com resíduos de agrotóxicos, metais pesados, hormônios e antimicrobianos ${ }^{[38]}$.

Leite orgânico é aquele produzido em sistema onde não há uso de agrotóxico sintético, antibióticos e outros insumos artificiais tóxicos e organismos geneticamente modificados, visando à oferta de produtos saudáveis e de elevado valor nutricional ${ }^{[39]}$. Porém, o tratamento veterinário das vacas leiteiras 
deve ser considerado um complemento, jamais um substituto das práticas de manejo. Devem ser buscadas alternativas naturais para o tratamento de enfermidades do rebanho, como o uso da homeopatia, que vem trazendo bons resultados e redução de custos na cadeia produtiva. O uso de substâncias promotoras de crescimento e modificadoras do ciclo reprodutivo é contrário aos princípios da produção orgânica e é, pois, proibido ${ }^{[40]}$.

O leite orgânico apresenta diferenças na composição química quando comparado ao leite produzido pelo sistema convencional. Estudo que avaliou as características físico-químicas de leite orgânico demonstrou que o perfil nutricional desse tipo de produto revelou um maior teor de proteínas, menor teor de gordura e menor percentual de gordura saturada; os principais ácidos graxos não apresentaram diferenças significativas entre os tipos de leite analisados, porém foi encontrado maior teor de ácido linoléico quando comparado ao leite produzido em sistemas convencionais, o que se deve provavelmente à dieta diferenciada dos animais leiteiros ${ }^{[38]}$.

No Brasil, ainda existem poucos produtores de leite orgânico e a literatura mais recente dispõe de poucos dados sobre o leite orgânico produzido no país ${ }^{[38]}$. Os maiores empecilhos para o aumento da produção de leite orgânico e seus derivados são a carência de empresas que processem esse tipo de leite, aliada à baixa produtividade do sistema orgânico em relação ao sistema convencional de produção de leite ${ }^{[41]}$.

\section{CONSIDERAÇÕES FINAIS}

A problemática da presença de antimicrobianos em leite tem relação intrínseca com o sistema de produção. A saúde do rebanho deve ser mantida de modo a assegurar a produção de alimentos inócuos, garantindo sua segurança, e permitindo, ao mesmo tempo, condições de competitividade dentro da cadeia leiteira. A fonte do problema, contudo, parece estar justamente na tentativa de se evitarem prejuízos econômicos decorrentes de problemas com o rebanho. A utilização de doses sub-terapêuticas, usadas preventivamente contra infecções e como promotores de crescimento, bem como a administração de antibióticos sem respeitar os períodos de suspensão prescritos no período próximoà ordenha, demonstram claramente a intenção de alguns produtores de manter a competitividade à margem das recomendações de entidades internacionais e da legislação vigente.

Tem sido frequente a detecção, no Brasil, de antibióticos em leite em grandes quantidades. Apesar de ser um grande produtor de leite e derivados e possuir boas relações comerciais com países importadores, seus sistemas de legislação e fiscalização ainda se mostram ineficientes para a resolução do problema. Novas discussões acerca do tema devem ser lançadas, na tentativa de criação de condições para uma produção leiteira que respeite as regulamentações que vigoram no País.

A adoção das Boas Práticas de Fabricação em propriedades fornecedoras de leite seria uma solução bastante eficiente. Cabe, portanto, uma ação conjunta entre o poder público e a cadeia produtiva para minimizar os efeitos da presença desses resíduos no leite.

A agricultura orgânica ganha força a cada dia, mas a produção brasileira de leite orgânico ainda é incipiente. Os empecilhos que existem para o desenvolvimento da agricultura orgânica na esfera dos laticínios, contudo, não devem servir de desestímulo aos pequenos e grandes produtores. $\mathrm{O}$ vislumbre de novas alternativas para produção de leite e derivados que visem à eliminação dos resíduos nos produtos torna-se necessário, à medida que cresce cada vez mais a preocupação com o alcance da segurança alimentar, como forma de disponibilizar a todos os indivíduos alimentos de qualidade, sem qualquer tipo de contaminantes que coloquem em risco sua saúde.

\section{REFERÊNCIAS}

1. Lerayer ALS, Miguel AMRO, Guedes ALA, Carvalho AF, Itajdenwurcel JR, Fonseca LM et al. Nova legislação de produtos lácteos: Revisada, Ampliada e Comentada. São Paulo: Editora Revista Indústria de Laticínios; 2002.

2. Brasil. Lei oㅡ 11.346, de 15 de setembro de 2006. Cria o Sistema Nacional de Segurança Alimentar e Nutricional - SISAN, com vistas a assegurar o direito humano à alimentação adequada e dá outras providências. Diário Oficial da União, Brasília, 18 set. 2006. Seção 1, p. 1.

3. Monardes H. Reflexões sobre a qualidade do leite. In: Dürr J, Carvalho M, Santos M (org.) O compromisso com a qualidade do leite no Brasil. Passo Fundo: UPF Editora; 2004. p. 11-37. 
4. Frazier WC, Westhoff DC (org.) Microbiología de los alimentos. Zaragoza: Acribia; 1978.

5. Organización de las Naciones Unidas para la Agricultura y la Alimentación. Producción de alimentos de origen animal: código de prácticas de higiene para la leche y los productos lácteos - CAC/RCP 57-2004. $2^{a}$ ed. Roma: FAO/OMS; 2009.

6. World Health Organization. The Medical Impact of Antimicrobial Use in Food Animals. Report of a WHO Meeting. Berlin, Germany, 13-17 October 1997 [cited 2009 jun 23]. Available from: http://whqlibdoc.who.int/ hq/1997/WHO EMC ZOO 97.4.pdf

7. Gobbo SP. Padronização e desenvolvimento de reagentes imunoenzimáticos para pesquisa de ciprofloxacina em produtos de origem animal [tese]. Piracicaba: Universidade de São Paulo; 2006. 103 p.

8. Milkpoint [homepage]. Produção de leite - países selecionados [acesso em 2 nov 2011]. Disponível em: http://www.milkpoint.com.br/estatisticas/producao mundial.htm

9. Oliveira RPS. Condições microbiológicas e avaliação da pasteurização em amostras de leite comercializados no município de Piracicaba - SP [dissertação]. Piracicaba: Universidade de São Paulo; 2005. 81 p.

10. Brito MAVP, Brito JRF. Qualidade do leite. In: Madalena FH, Matos LL, Holanda Jr. EJ (Org.). Produção de leite e sociedade: uma análise crítica da cadeia do leite no Brasil. Belo Horizonte: FEPMVZ; 2001. p. 61-74.

11. Netto DP, Lopes MO, Oliveira MCS, Nunes MP, Machinski Junior M, Bosquiroli SL et al. Levantamento dos principais fármacos utilizados no rebanho leiteiro do Estado do Paraná. Acta Scientiarum. Animal Sciences. 2005;27(1):145-151.

12. Bruno F, Curini R, di Corcia AD, Nazzari M, Samperi R. Solid-phase extraction followed by liquid chromatographymass spectrometry for trace determination of $\beta$-lactam antibiotics in bovine milk. J Agric Food Chem. 2001;49(7):3463-70.

13. Schenck FJ, Callery PS. Chromatographic methods of analysis of antibiotics in milk. J Chromatogr A. 1998;812(1-2):99-109.
14. Tronco VM (org.). Manual para inspeção da qualidade do leite. 2a ed. Santa Maria: Ed. da UFSM; 2003.

15. Andrew SM, Moyes KM, Borm AA, Fox LK, Leslie KE, Hogan JS, Oliver YH, Schukken WE, Owens WE, Norman C. Factors associated with the risk of antibiotic residues and intramammary pathogen presence in milk from heifers administered prepartum intramammary antibiotic therapy. Vet Microbiol. 2009;134(1-2):150-6.

16. Costa EO. Uso de antimicrobianos na mastite. In: Spinosa HS (Org.). Farmacologia aplicada à medicina veterinária. Rio de Janeiro: Guanabara Koogan; 2002. p. 501-515.

17. Biacchi NC, Jorge AOC, Ueno M. Detecção de resíduos antibióticos em leite bovino na região do Vale do Paraíba, São Paulo. Revista Biociências. 2004;10(1-2):47-9.

18. Empresa Brasileira de Pesquisa Agropecuária [homepage]. Resistência antimicrobiana $\mathrm{x}$ produção animal: uma discussão internacional; 2004 [acesso em 23 jun 2009]. Disponível em: http://www.embrapa.br/imprensa/ artigos/2000/artigo.2004-12-07.2546062632

19. Nascimento GGF, Maestro V, Campos MSP. Ocorrência de resíduos de antibióticos no leite comercializado em Piracicaba, SP. Rev Nutr. 2001;14(2):119-24.

20. Dewdney JM, Maes L, Raynaud JP, Blanc F, Scheid JP, Jackson T, Lens S, Verschueren C. Risk assessment of antibiotic residues of beta-lactams and macrolides in food products with regard to their immuno-allergic potential. Food Chem Toxicol. 1991;29(7):477-83.

21. Lederer J (Org.). Enciclopédia moderna de higiene alimentar: intoxicações alimentares. São Paulo: Manole; 1991.

22. Virginia Cooperative Extension [homepage]. Virginia: Publication and Resources [cited 2009 jun 23]. Available from: http://pubs.ext.vt.edu/404/404-401/404-401.html

23. Costa EO. Resíduos de antibióticos no leite: um risco à saúde do consumidor. Hig aliment. 1996;10(44):15-7.

24. Bando E, Oliveira RC, Ferreira GM, Machinski M. Occurrence of antimicrobial residues in pasteurized milk commercialized in the state of Paraná, Brazil. J Food Prot. 2009;72(4):911-4.

25. Hsieh SH, Huang HY, Lee S. Determination of eight penicillin antibiotics in pharmaceuticals, milk and porcine tissues by nano-liquid chromatography. J Chromatogr A. 
2009;1216(43):7186-94.

26. Chung H-H, Lee J-B, Chung Y-H, Lee K-G. Analysis of sulfonamide and quinolone antibiotic residues in Korean milk using microbial assays and high performance liquid chromatography. Food Chem. 2009;113(1):297-301.

27. Yamaki M, Berruga MI, Althaus RL, Molina MP, Molina A. Occurrence of antibiotic residues in milk from Manchega ewe dairy farms. J Dairy Sci. 2004;87(10):3132-7.

28. Mohamadi Sani A, Nikpooyan H, Moshiri R. Aflatoxin M1 contamination and antibiotic residue in milk in Khorasan province, Iran. Food Chem Toxicol. 2010;48(8-9):2130-2.

29. Nero LA, Mattos MR, Beloti V, Barros MAF, Franco BDGM. Resíduos de antibióticos em leite cru de quatro regiões leiteiras no Brasil. Ciênc Tecnol Aliment. 2007;27(2):391-3.

30. Borges GT, Santana AP, Mesquita AJ, Mesquita SQP, Silva LAF, Nunes VQ. Ocorrência de resíduos de antibióticos em leite pasteurizado integral e padronizado produzido e comercializado no estado de Goiás. Ci Anim Bras. 2000;1(1):59-63.

31. Tetzner TAD, Benedetti E, Guimarães EC, Peres RFG. Prevalência de resíduos de antibióticos em amostras de leite cru na região do Triângulo Mineiro, MG. Hig aliment. 2005;19(130):69-72.

32. Mendes CG, Sakamoto SM, Silva JBA, Leite AI. Pesquisa de resíduos de beta-lactâmicos no leite cru comercializado clandestinamente no município de Mossoró, RN, utilizando o Delvotest SP. Arq Inst Biol. 2008;75(1):95-8.

33. Mercosul. Resolução GMC (Grupo Mercado Comum) no 54, de 29 setembro de 2000. Regulamento Técnico Metodologias Analíticas, Ingestão Diária Admissível e Limites Máximos de Resíduos Para Medicamentos Veterinários em Alimentos de Origem Animal. Disponível em: $\quad$ http://www.mercosur.int/msweb/Normas/ normas web/Resoluciones/PT/Res 054000 RTM\%20Res\%C $3 \%$ ADduos $\% 20$ Medic $\% 20$ Veterin $\%$ C3\%A1rios Ata $\% 203$ 00.PDF

34. Brasil. Ministério da Agricultura, Pecuária e Abastecimento. Instrução Normativa no 42, de 20 de dezembro de 1999. Altera o Plano Nacional de Controle de Resíduos em Produtos de Origem Animal - PNCR e os Programas de Controle de Resíduos em Carne - PCRC, Mel - PCRM,
Leite - PCRL e Pescado - PCRP. Diário Oficial da União, Brasília, 22 dez. 1999. Seção 1, p. 253.

35. Associação Brasileira das Pequenas e Médias Cooperativas e Empresas de Laticínios Laticínios [homepage]. Legislação sobre a fiscalização de produtos lácteos. Série Lácteos Seguros, artigo no 6 [cacesso em 20 maio 2009]. Disponível em: http://www.g100.org.br/ download/ Lacteos SegurosVI.pdf

36. Brasil. Ministério da Saúde. Programa de Análise de Resíduos de Medicamentos Veterinários em Alimentos Expostos ao Consumo - PAMVet [acesso em 2 maio 2009]. Disponível em: http://www.anvisa.gov.br/ alimentos/pamvet/pamvet.pdf

37. Planeta Orgânico [homepage]. O Papel do consumidor no mercado de produtos orgânicos. [acesso em 23 jun 2009]. Disponível em: http://www.planetaorganico.com.br/ trabdarolt1.htm

38. Fanti MGN, Almeida KE, Rodrigues AM, Silva RC, Florence ACR, Gioielli LA et al. Contribuição ao estudo das características físico-químicas e da fração lipídica do leite orgânico. Ciênc Tecnol Aliment. 2008;28(Supl.):259-65.

39. Brasil. Lei no 10.831, de 23 de dezembro de 2003. Dispõe sobre a agricultura orgânica e dá outras providências. Diário Oficial da União, Brasilia, 24 dez. 2003. Seção 1, p. 8.

40. Aroeira LJM, Paciullo DSC, Fernandes EN. Produção orgânica: enfoque leite, suas implicações e consequências. In: Stringheta PC, Muniz JN (Org.). Alimentos orgânicos: produção, tecnologia e certificação. Viçosa: Editora UFV; 2003. p. 155-194.

41. Brandão IF. Condicionantes do consumo de leite orgânico em Minas Gerais [tese]. Viçosa: Universidade Federal de Viçosa; 2005. 74 p. 